\title{
ANALYSING UBER IN SOCIAL MEDIA - DISRUPTIVE TECHNOLOGY OR INSTITUTIONAL DISRUPTION?
}

\author{
CHRISTOFER LAURELL \\ Stockholm Business School, Stockholm University \\ SE-106 91, Stockholm, Sweden \\ cpi@sbs.su.se \\ CHRISTIAN SANDSTRÖM* \\ Chalmers University of Technology and the Ratio Institute \\ SE-412 96, Göteborg, Sweden \\ christian.sandstrom@chalmers.se
}

Published 11 May 2016

\begin{abstract}
Extant literature suggests that market disruptions take place because of two main reasons: technological disruption or institutional change. In view of these two alternative explanations, this paper aims to explore how the recent rise of the collaborative consumption platform Uber is perceived by consumers and whether this platform is primarily regarded as a technological innovation or as an institutional disruption. Drawing from a dataset of more than 6500 user-generated contents in social media, our findings suggest that Uber is not primarily perceived as a technological innovation, but rather as an institutional disruption.
\end{abstract}

Keywords: Technological disruption; customer preferences; performance measures; entrants; institutional disruption; institutional transformation; collaborative consumption platforms; Uber; social media; social media analytics.

\section{Introduction}

Information and communication technologies (ICTs) enable new forms of value creation (Pihl, 2014; Pihl and Sandström, 2013). In recent years, collaborative

\footnotetext{
*Corresponding author.
}

This is an Open Access article published by World Scientific Publishing Company. It is distributed under the terms of the Creative Commons Attribution 4.0 (CC-BY) License. Further distribution of this work is permitted, provided the original work is properly cited. 
consumption platforms have gained momentum in several sectors of the economy. Entrant firms such as AirBnB, Taskrabbit and Uber are growing rapidly and threaten established players by introducing new business models that create lower prices, new performance parameters and new levels of scalability. While there are many examples of collaborative consumption models on the internet, their impact on established industries and physical marketplaces remains understudied.

Collaborative consumption firms introduce an offering that clearly posit some disruptive properties in the sense that value is created in novel ways, often by introducing new performance parameters (Bower and Christensen, 1996). It was however argued in a recent publication that Uber does not fulfil the traditional criteria for being regarded as a disruptive innovation (Christensen et al., 2015). At the same time, Uber and many similar firms create institutional turbulence, largely by circumventing existing rules, taxes and regulations. The actions of these firms can thus be thought of as a form of institutional entrepreneurship as they do not compete according to established rules and norms, but rather by altering the institutional set-up governing an industry.

As these phenomena are relatively new, it is still unclear how collaborative consumption platforms emerge within an established institutional setting and how they are received by the market. The purpose of this paper is therefore to explore whether Uber, a personal transportation platform, is conceived of as a technological innovation, and/or as an institutional disruption. This is done by analysing how Uber is discussed in social media. Given current discourse about whether Uber is disruptive or not and the ongoing public debates about this case, it is important to investigate in further detail whether Uber is primarily a technological or institutional disruption.

Applying social media analytics and coding more than 6500 posts, our findings suggest that Uber is perceived both as a technological innovation and an institutional transformation. The institutional disruption is however significantly more prevalent in social media discourse.

The paper is organised as follows. The next section reviews literature on technological discontinuities and theory on institutional change. The subsequent chapter describes the social media analytics method employed in this article. Next, our data is presented and analysed. Eventually, a concluding remark is provided.

\section{Elements of the Topic}

A growing and well established body of literature has studied how radically new technology emerges and enters the market. It is well documented today that technology tends to evolve through periods of evolutionary change, which may at 
times be punctuated by the emergence of a new trajectory (Abernathy and Utterback, 1975; Utterback, 1994). The rise of a new technology frequently results in an era of ferment (Anderson and Tushman, 1990). As the technology eventually settles on a dominant design, uncertainty is significantly reduced and an industry starts to consolidate. Technological change therefore has far reaching implications, not only when it comes to the competitive landscape of an industry (Tripsas, 1997), but also the offerings provided to the market (Christensen, 1997). Also, new technology may alter established institutional settings (Laurell and Sandstrom, 2014) and create regulatory turbulence (Saunders, 1986; Ernkvist, 2015), hereafter referred to as institutional disruptions.

Broadly speaking, one domain of literature has dealt with the interaction between technology supply and market demand. Another field has concerned itself with the interplay between institutions and new technology. Here, institutions can be defined as "the humanly devised constraints that structure human interaction" (North, 1990: 3). These two categories of literature are described in further detail below.

\section{Technology supply and demand}

The emergence of new technology is frequently addressed and studied by looking into the interactions between technology supply and demand. Starting with technology supply, a number of scholars have argued that a new technology is likely to emerge when the performance of the previous solution has reached its limits (Sahal, 1985). This pattern is commonly known as a technology S-curve (Foster, 1986).

Other scholars have pointed out that the notion of technological limits may have some explanatory and predictive value, but that the interplay between the market and various technological offerings need to be analysed in further detail (Christensen, 1992). In a series of articles in the 1990s, Clayton Christensen argued that new technologies tend to offer a different combination of performance attributes. In the disk drive industry, new disks drives had worse storage capacity, but were often smaller, simpler and cheaper thereby creating an entirely new market or prospered in a low-end segment (Christensen and Rosenbloom, 1995; Christensen and Bower, 1996). Disruptive technologies may also emerge in a high-end segment, the main distinguishing feature seems to be that these technologies enable novel forms of value creation (Sandström, 2011).

To further understand the interplay between new technology and its diffusion, it is important to look at performance thresholds. In order to gain acceptance, a technology needs to have reached an acceptable level of performance along a set of dimensions (Adner, 2002). Adner further argued that there are two thresholds: 
the functional one sets the minimum performance that can be tolerated and the net utility threshold also takes price into consideration.

Other streams of research in this area have maintained more sociological perspectives upon the diffusion of innovations (Rogers, 1995). Relaxing assumptions of rational, self-maximising behaviour, this domain of literature has instead argued that diffusion is fundamentally a social process and that new technology gains acceptance if it caters to the customs, norms and values of the market. The diffusion of innovation is therefore thought of as an epidemic pattern, where one individual's decisions to adopt a novelty influences the decisions of others, resulting in an exponential increase, followed by saturation.

The literature reviewed above has in common that it largely regards customer preferences as predefined and somewhat static (Sandström et al., 2014). Addressing this gap in research, Tripsas (2008) introduced the notion of customer preference discontinuities, stating that demands in the market may be subjected to discontinuous change in the same way as technology might be. Consequently, firms need to pay close attention to altering preferences in the marketplace (Clark, 1985).

\section{Technological change and institutional disruption}

The emergence of new technology may also have far reaching implications with regard to the institutional setup in a certain industry (Jacobsson and Bergek, 2003; Pihl, 2013; Ernkvist, 2015). Such changes are not fully captured by literature on technology supply and demand. Broadly speaking, institutions can be defined as the "rules of the game" or as "regulative, normative, and cognitive structures and activities that provide stability and meaning to social behavior" (Scott, 1995: 33). Established institutions create stability and reduce transaction costs (Peng et al., 2009) and can be thought of as those factors which govern and mediate the interaction between technology supply and demand.

Within a certain organisational field, firms tend to subscribe to the same institutions, referred to as institutional isomorphism (DiMaggio and Powell, 1983). Put differently, organisations in a certain field imitate each other, they follow the same formal and informal rules, and these rules in turn define the organisational field.

The institutional perspective on technological change is different as institutions are not concerned with supply and demand on a market, but rather with the informal and formal rules that govern the interactions between demand and supplied offerings. Agency directed towards changing institutions is commonly defined as institutional entrepreneurship (Peng and Heath, 1996; DiMaggio, 1998). This form of change is often referred to as divergent as such processes result in an era of ferment in the institutional domain, which at times is triggered by 
technological change (Garud et al., 2002). These periods of instability are frequently characterised by conflicting interests, struggles for power and attempts to demarcate what constitutes a certain organisational field.

\section{Synthesis}

The emergence of a radically new technological innovation may have far reaching implications along several different dimensions. New technology may result in improved performance along an established parameter, but can also generate an entirely different value proposition. It can also alter the preferences of customers, resulting in a punctuated equilibrium in the demand function. Innovations may also distort established institutional regimes, altering the rules of the game.

Collaborative consumption platforms seem to offer a new value proposition. Given the extensive media attention around Uber and the regulatory turbulence it has imposed upon the taxi industry, it seems that those platforms are also at times distorting established institutions. It is therefore of empirical and theoretical interest to assess the relative magnitude of those two factors and possibly point out which of those factors seems to be the dominant one. In this paper, we therefore investigate the impact Uber has had on customer discourse about the taxi industry.

\section{Method}

We study Uber's impact on the taxi industry by analysing publicly posted, usergenerated contents in different social media platforms. Methods related to the collection and analysis of user-generated content, as well as social media in general, has over recent years become an increasingly discussed topic and has resulted in the emergence of social media analytics (SMA). By gathering and coding entries about Uber on various social media platforms, we are able to study whether the marketplace perceives Uber as a disruptive technological innovation and/or an institutional innovation.

The SMA approach is interdisciplinary and seeks to combine, extend and adapt methods for analysis of social media data (Stieglitz et al., 2014). While the purposes of applying SMA vary across disciplines, innovation management has been suggested to represent one of the settings where this methodological approach is particularly useful. This is because social media have been suggested to be represent "a kind of living lab, which enables academics to collect large amounts of data generated in a real-world environment" (Stieglitz et al., 2014: 90) that also provides a methodical approach that is relatively unobtrusive in its nature. 


\section{Laurell \& C. Sandström}

\section{Data collection}

The relatively fragmented social media landscape and the lack of standardised ways to gain access to user-generated content across platforms represent one of the main challenges that SMA researchers face during data collection. The increasing demand to access social media data particularly among researchers but also practitioners has generated a flora of software services offering structured access across platforms.

For the purpose of data collection for the present study, one of these services was used. As other alternative services, notified has been developed to capture user-generated contents published on a diverse set of social media platforms. When using the tool, the user first enters one or a set of keywords. After the keyword, or the set of keywords has been entered, all publically published usergenerated contents from Twitter, Instagram, Facebook, blogs, forums and YouTube are collected in a database in real-time. Thus, the tool allows for researchers to collect data from a relatively broad set of social media applications found in the social media landscapes in a structured manner. This also means that the researcher does not need to use problematic data collection methods, such as scraping techniques (Stieglitz et al., 2014).

For the purpose of this study, the keyword "Uber" was entered into the service on the 16th of June. Data was thereafter collected up until the 16th of August. This generated a dataset amounting to 6550 social media posts covering a time period of two months. This dataset only contains user-generated contents written in Swedish or user-generated contents written in English posted by Swedish users. The rationale for doing so was twofold. First, filtering the data collection process to a specific language and user origin allowed for a more focused data collection process. Doing so is important as certain keywords tend to have several connotations in different languages and also be either rare or common in the everyday vocabulary of different languages. In the case of Uber, the usage of this word in the Swedish language is strongly limited. Therefore, user-generated contents including the keyword "Uber" were assumed to have a relatively high degree of relevance in relation to the phenomenon in question. Second, Sweden is one of the countries that tend to top the global ranking of digital technology usage as well as high speed Internet access which makes its social media landscape particularly vibrant (Findahl and Davidsson, 2015) and therefore suitable for the purpose of SMA.

\section{Data analysis}

Following data collection, the dataset was analysed by applying content analysis in three sequential steps. In the first step, the dataset was reviewed in order to exclude 
Table 1. Collected and publicly posted user-generated contents per social media platform.

\begin{tabular}{lcc}
\hline Social media & Number of contents & Share (\%) \\
\hline Blog & 144 & 3,0 \\
Facebook & 106 & 2,2 \\
Forum & 198 & 4,1 \\
Twitter & 4422 & 90,8 \\
Total & 4870 & 100 \\
\hline
\end{tabular}

user-generated contents relating to other phenomena then the one in question. This review identified 1680 user-generated contents relating to other phenomena. These contents were therefore excluded from the dataset, resulting in a total amount of 4870 remaining user-generated contents. Table 1 presents the distribution of these user-generated contents across social media platforms.

In the second step, content analysis was carried out by qualitatively reviewing the dataset with the purpose of identifying central themes in the material. This was done by reviewing the 1000 first user-generated contents from the beginning of the studied time period, which resulted in four preliminary themes as well as associated sub-themes. The four preliminary themes consisted of user-generated contents that either focused its attention (i) solely on Uber, (ii) Uber in relation to one or several competitors, (iii) the transformation of personal transportation as a result of Uber, or (iv) the societal consequences and potential implications of Uber's entry. With the help of these preliminary themes and associated sub-themes, the total material was thereafter reviewed a second time. After this process had been carried out, and minor adjustments had been implemented in regards to the subthemes, the final respective themes as well as associated sub-themes were drawn and coded across the material. These included four themes and thirteen associated subthemes.

In the third step, quantitative content analysis was applied by reviewing the frequencies of the identified themes and sub-themes over the studied time period. By doing so, the relative dominance of particular themes and sub-themes in terms of their frequency over time was studied in further detail.

\section{Results}

In the following sections, the results of the conducted analyses are presented in two steps. First, the identified themes and subthemes are described. This is followed by data on the frequencies of these themes and subthemes over the studied period. 


\section{Laurell \& C. Sandström}

\section{Themes and sub-themes}

Based on the conducted content analysis, four themes and thirteen associated subthemes emerged from the material. Table 2 presents the respective themes and their associated sub-themes, as well as providing illustrative examples drawn from the dataset. As the table illustrates, the respective themes are derived from the two literature domains described above, namely technological disruption and institutional disruption. For the respective literature, two main themes and 6-7 subthemes were drawn from the data.

Table 3 presents the frequency of each sub-theme as well as the sub-total of the respective main themes. For the total material, a majority of $59.6 \%$ of the usergenerated contents where neutral in their character while $20.4 \%$ were positive and $19.9 \%$ negative.

User-generated contents that are centred only on Uber is the most commonly identified theme representing $51.9 \%$ of the total material. Meanwhile, user-generated contents that are centred on Uber and one or more of their competitors represents $3.4 \%$ of the total material. Within these two main themes, which together represent $55.3 \%$, neutral organisational references are the ones most commonly articulated. When regarding the remaining six sub-codes, which explicitly states a positive or negative preference, the total number amounts to 1050 user-generated contents, representing $21.6 \%$ of the total material.

Within this material, commonly explicated preferences revolve around two main categories. In the first category, which spans across Uber as well as their competitors, stated preferences are oriented around price, service, convenience, safety, punctuality, experience and trustworthiness. One illustrative example that encompasses two of these preferences was published on the 18th of June 2015:

"Hi Taxi Stockholm, I've been traveling with you for 10 years, three times a day. Do you have any argument for why I should choose to ride with you instead of Uber? As a consumer I obviously want to choose the most affordable option, with high service, and at the same time contribute so the driver gets the optimal compensation. Attached, you find a screenshot from my latest trip, from Midsommarkransen to Hornstull - SEK 52. Which would correspond to your base-fare. Please tell me what I'm missing out on, that I do not get through Uber."

In the second category, which is centred around Uber, explicated preferences either concern the mobile application or the actual and potential integration of other applications and services. In regards to the former, two illustrative examples 


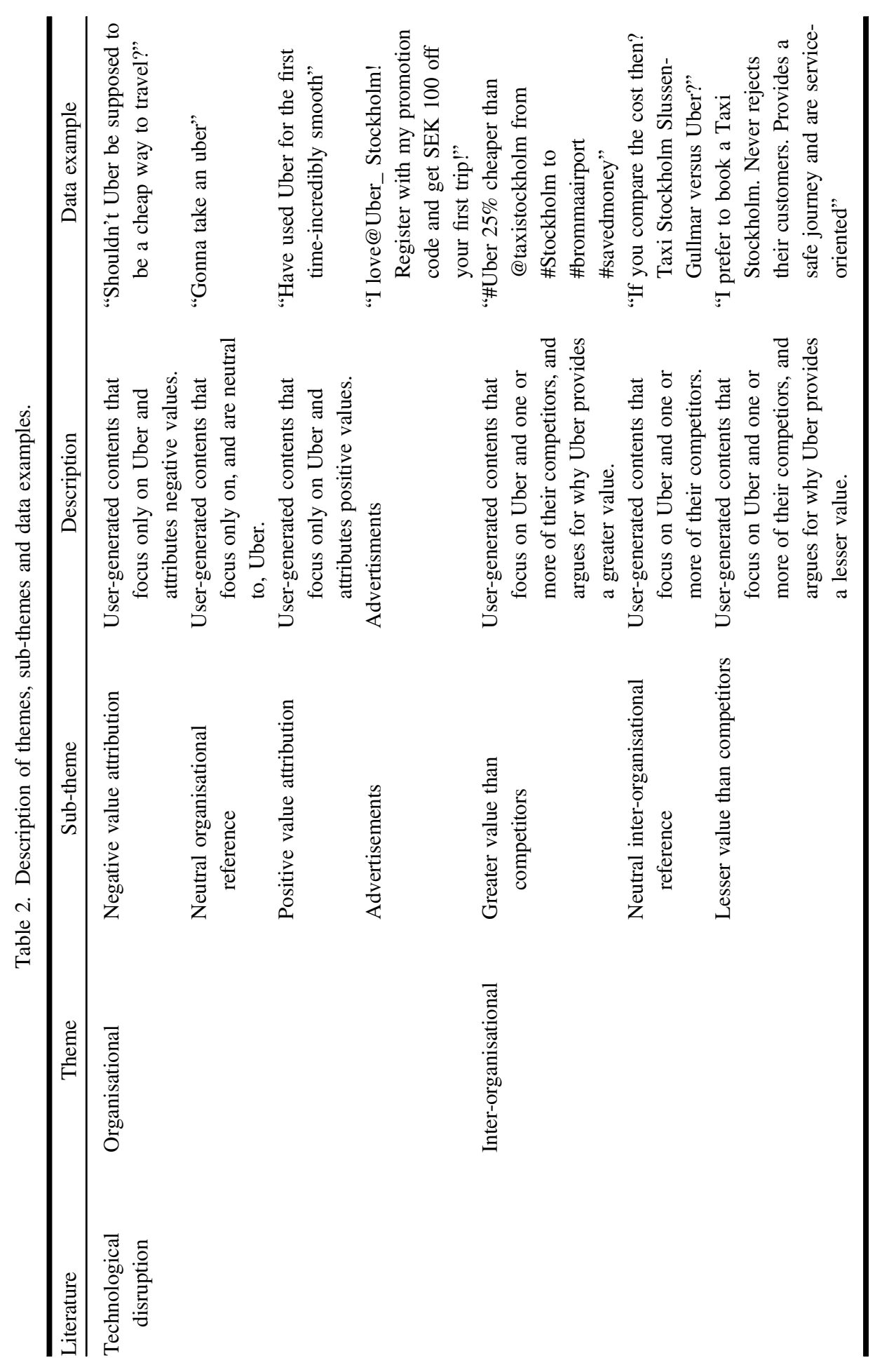




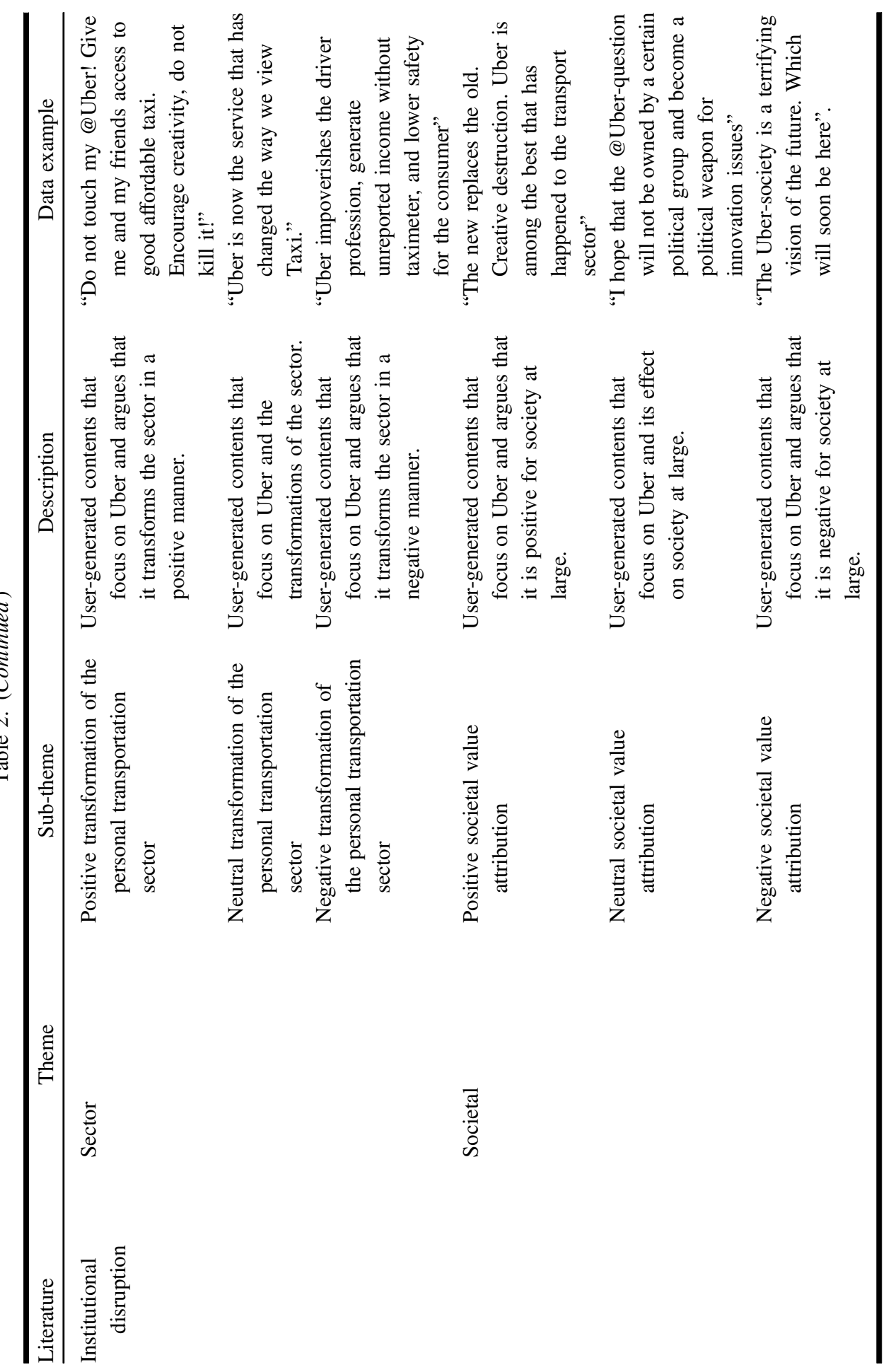


Table 3. Frequency of themes and sub-themes.

\begin{tabular}{|c|c|c|c|}
\hline Literature & Theme & Sub-theme & Frequency \\
\hline \multirow{9}{*}{$\begin{array}{l}\text { Disruptive } \\
\text { Technology }\end{array}$} & Organisational & Negative value attribution & 410 \\
\hline & & Neutral organisational reference & 1642 \\
\hline & & Positive value attribution & 369 \\
\hline & & Advertisements & 104 \\
\hline & & Sub-total & 2525 \\
\hline & Inter-organisational & Greater value than competitors & 127 \\
\hline & & Neutral inter-organisational reference & 29 \\
\hline & & Lesser value than competitors & 11 \\
\hline & & Sub-total & 167 \\
\hline \multirow[t]{8}{*}{$\begin{array}{l}\text { Institutional } \\
\text { Disruption }\end{array}$} & Sector & $\begin{array}{l}\text { Positive transformation of the personal } \\
\text { transportation sector }\end{array}$ & 71 \\
\hline & & $\begin{array}{l}\text { Neutral transformation of the personal } \\
\text { transportation sector }\end{array}$ & 1161 \\
\hline & & $\begin{array}{l}\text { Negative transformation of the personal } \\
\text { transportation sector }\end{array}$ & 68 \\
\hline & & Sub-total & 1300 \\
\hline & Societal & Positive societal value attribution & 407 \\
\hline & & Neutral societal value attribution & 9 \\
\hline & & Negative societal value attribution & 462 \\
\hline & & Sub-total & 878 \\
\hline
\end{tabular}

were posted on the 18th of August 2015 and the 27th of July 2015:

"The app Bar Roulette sends you to a randomly top rated bar near where you are using Uber and Yelp. Excellent abroad."

"Can you not combine Uber and Tinder? The worst thing is that I will never come home.. \#tinder \#Uber"

In regards to user-generated contents that focus on Uber and the transformation of the personal transportation sector, this theme represents $26.7 \%$ of the total material. Meanwhile, user-generated content concerning Uber and its societal consequences represents $18.0 \%$ of the total material. Within these two main themes, that together represent $44.7 \%$ of the total material, neutral contents are the most frequently occurring in regards to the transformation of the sector while positive or negative contents dominate in regards to the societal implications.

In terms of topical discussions found within these two main themes, one particular issue is predominant across them both. More specifically, this issue relates to whether Uber and Taxi should be regarded as either one and the same or two 


\section{Laurell \& C. Sandström}

distinctly different personal transportation service offerings. One example of how this is commonly explicated was published the 17th of August 2015:

"For those of you who do not know, Uber is a cheaper alternative to taxi."

As the potential implications for Uber are significant, in terms of either being a distinctly separated service or being a part of the established taxi industry, these contents tend to be relatively conflict oriented. One example of a content that supports Uber was posted 6th of July 2015:

"I do not understand why ordinary people do not advocate \#Uber, prior to regular taxi that often cheat with the price and generally are bad."

\section{Themes and sub-themes over the studied period}

Looking at the distribution of main themes and sub-themes for the total material, Fig. 1 presents the frequency of the main themes over the period. As the figure illustrates, user-generated contents which are centred solely on Uber (organisational), Uber and the transformation of the personal transportation (sector) or Uber and its societal implications (societal) are particularly common during periods of increased social media engagement.

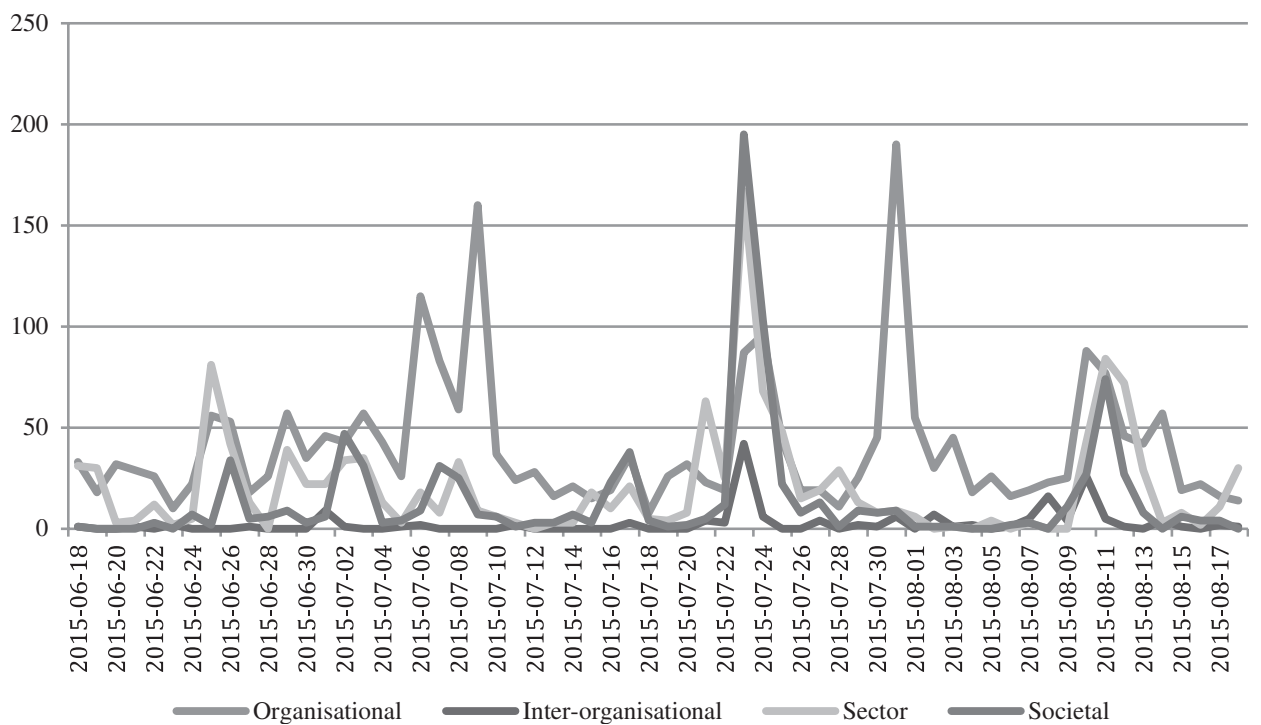

Fig. 1. Frequency of main themes over the studied time period. 


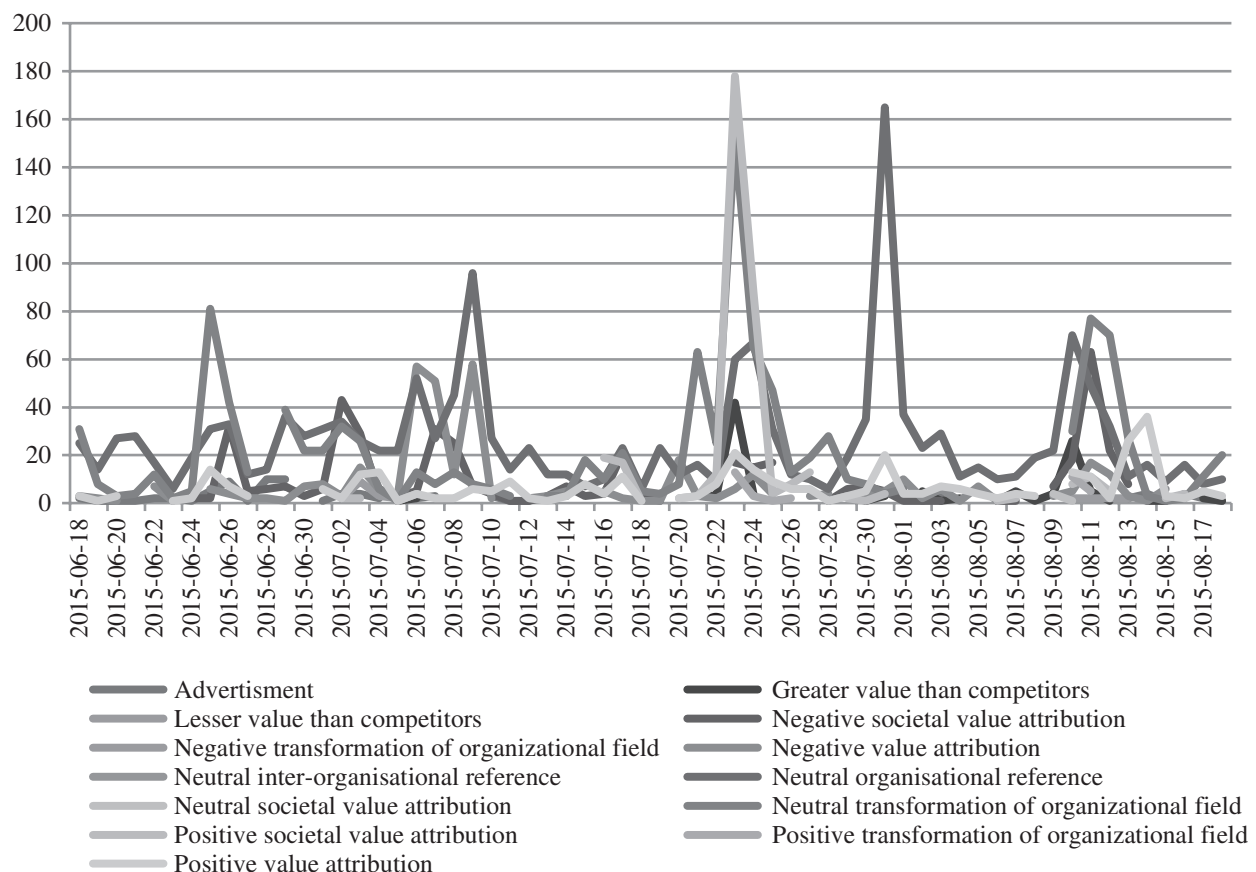

Fig. 2. Frequency of sub-themes over the studied time period.

Figure 2 presents the frequency of the sub-themes over the studied period. As the figure illustrates, user-generated contents in terms of neutral references to Uber, neutral contents relating to Uber and the transformation of the personal transportation and positive contents in regards to the societal implications of Uber are particularly common during of periods of increased social media engagement as illustrated in Fig. 1.

\section{Analysis and Discussion}

The results presented above show that a considerable amount of social media users take part in posting user-generated contents revolving around Uber and with relatively varying sentiments. In order to analyse the distribution of published contents for the total period, as well as over time, the following three subsections will address the results in relation to technological disruptions, institutional disruptions and the interplay between these two.

\section{Technological disruption}

As illustrated in regards to the two main themes relating to technological disruption, the contents that focus on Uber or Uber in relation to its competitors has 
been given significant attention. $21.6 \%$ of the user-generated contents (1050 posts) concern the actual offering, i.e., how users perceive Uber or how Uber relates to one or more competitors.

Among the commonly explicated preferences, these can in terms of performance measures be understood to represent both previously established measures (price, service, convenience, safety, punctuality, experience and trustworthiness) as well as measures introduced as a result of Uber (mobile application and the actual or potential integration of other applications and services). Many articulations of user preferences concern price and the fact that Uber tends to offer a service that is cheaper. The following post in Table 2 can be regarded as an illustrative example:

“\#Uber 25\% cheaper than @ taxistockholm from \#Stockholm to \#brommaairport \#savedmoney"

Uber's entry into the taxi market can therefore be analysed and understood as a new technological solution, competing with an established solution. As such, Uber's offer clearly has some disruptive properties in the sense that it creates value in new ways, for instance by being simpler, cheaper and reducing costs (Christensen and Bower, 1995). Before a solution gains acceptance in the market, it must also reach certain acceptable performance levels (Adner, 2002) and current levels of diffusion suggest that this is also the case.

In view of this development, it can also be argued that the traditional taxi industry has reached its performance limits and that Uber's solution transcends established tradeoffs with regard to e.g., price, service, convenience and reliability (Sahal, 1985). It is, however, noteworthy that a relatively small share of the published posts found in the material actually concern Uber's offering, its value and how it compares to established solutions. Hence, it clear that Uber has introduced a new offer, but that the actual value of this offer vis-à-vis previous solutions is only perceived to a limited extent.

\section{Institutional disruption}

A considerable share of the published user-generated contents about Uber is devoted to topics related to institutional change (44.7\%). Furthermore, one of the more frequent topical discussions spanning across these two themes revolves around whether Uber is a separate service or whether it belongs to the established taxi sector. Several examples in Table 2 illustrate the on-going discourse about the taxi industry and its boundaries:

"Uber is now the service that has changed the way we view Taxi." 
"The new replaces the old. Creative destruction. Uber is among the best that has happened to the transport sector"

Discussions concerning Uber and the taxi industry revolve around users either supporting or rejecting the idea of Uber belonging to the industry. By publically showing their stance, users contribute to the collective perception of both Uber and the boundaries of the sector. As such, Uber seems to engage in institutional entrepreneurship, as it alters and/or circumvents formal and informal institutions (DiMaggio and Powell, 1988). Institutional change is frequently characterised by diverging views and an era of ferment, this is also illustrated in our empirical data (Table 2):

"I hope that the @Uber-question will not be owned by a certain political group and become a political weapon for innovation issues"

"The Uber-society is a terrifying vision of the future. Which will soon be here."

These results do not only provide clear indications that Uber is perceived as an institutional disruption. It also shows the willingness of users to contribute in the process of defining the boundaries of particular sectors, but more importantly suggests that that the role of social media users might materialise as either supporting or rejecting the efforts of entrants and to a degree thereby participate in the transformation of markets.

\section{Technological disruption and institutional disruption}

Comparing the results above, we can conclude that Uber posits several disruptive characteristics that are discussed and assessed by users. $21.6 \%$ of all social media content around Uber is related to the value of using Uber, either about the service itself or by comparing it to competitors from the established taxi industry. These posts revolve around more objective traits such as price, reliability etc.

The institutional turbulence receives more than twice as much attention (44.7\%), indicating that Uber is first and foremost perceived as an institutional disruption rather than a technological innovation. While our data does not address whether Uber fulfils the specific and more conventional definition of a disruptive technology (Bower and Christensen, 1995), it clearly shows that such discussions focusing on the performance criteria for being disruptive should be regarded as more peripheral (see Christensen, et al., 2015). Uber entry into the Taxi industry has primarily induced institutional turbulence and it is of less importance whether it meets certain criteria for being regarded as a disruptive innovation or not. 


\section{Discussion and future research}

As the case of Uber has illustrated, the perception of institutional disruption is considerably more important than the specific characteristics of Uber's offer.

The studied case arguably represents a platform that has come relatively far in terms of market diffusion, especially considering the size of the markets that the platform has entered. This could potentially be one explanation to the high proportion of perceived institutional disruption in contrast to technological disruption.

Though discussions of Uber's offering are less frequent, they are still present. As it is well documented that technology tends to evolve through periods of evolutionary change and occasional punctuations (Abernathy and Utterback, 1975; Utterback, 1994), our findings may suggest that the interplay between technological and institutional disruption follow a similar pattern.

As performance thresholds are reached (Adner, 2002), other collaborative consumption platforms might also generate institutional turbulence. As this occurs, the potential perceptual shift from technological disruption to institutional change takes place, and thereby interlinks these previously separate conceptual processes. The interplay between technology lifecycles and institutional change merits further research, especially regarding collaborative consumption platforms and how they differ.

As collaborative consumption platforms are emerging within several sectors of the economy, individual platforms may potentially differ in terms of the balance between technological and institutional disruption. As this study has been limited to one particular platform, research which spans across platforms would be of particular value as such studies could help to (i) reveal particular evolutionary phases of the interplay between technological and institutional disruptions, and (ii) help to further explain the effects of collaborative consumption platforms on traditional market arrangements.

Another direction for future research revolves around the role of users in social media. The presented study has illustrated how users of social media devote themselves to either supporting or rejecting changes that take place within a certain sector. Based on these illustrations, the potential role of social media as a source of institutional pressure for both individual organisations as well as sectors represent an area where more knowledge is needed, particularly regarding business models that are formed in digital contexts and in close proximity to social media participation.

In view of these potential avenues for future research, the SMA approach offers methodologically relevant tools. The initial character of social media posed several challenges in regards to the usage of user-generated content, as content tended to be scattered across the social media landscape and being produced by a relatively 
homogenous user group. As the social media landscape has evolved, however, and now is centred on a number of dominating platforms where a vast plethora of users interact, this development has contributed considerably to the relevance and potential of utilizing social media data for the purpose of innovation research.

\section{Concluding Remarks}

This paper has explored whether the collaborative consumption platform Uber is primarily perceived as a disruptive innovation enabled by ICTs, or as an institutional disruption. Based on the presented results, this paper has contributed to extant literature by illustrating the presence of both dimensions, while also assessing the relative importance of them. Our findings suggest that Uber is first and foremost perceived as an institutional disruption, but that it is also to an extent regarded as a disruptive technology.

The paper therefore adds to a relatively small amount of research that seeks to address the relative magnitude of different forms of change when new technology is introduced. With some notable exceptions (Henderson, 1993; Tripsas, 1997), there are few studies which explicitly try to deal with several factors simultaneously and assessing their relative importance. We welcome future research about the interplay between technological and institutional change, especially investigations of how collaborative consumption platforms disrupt established industries.

\section{Acknowledgments}

An earlier version of this article received valuable feedback at the ISPIM Innovation Summit in Brisbane, Australia, 6-9 December 2015. Christofer Laurell would like to thank The Swedish Foundation for Humanities and Social Sciences (Riksbankens Jubileumsfond) for their financial support of his research.

\section{References}

Abernathy, WJ and JM Utterback (1978). Patterns of industrial innovation. Technology Review, 80(7), 40-47.

Adner, R (2002). When are technologies disruptive? A demand-based view of the emergence of competition. Strategic Management Journal, 23, 667-688.

Anderson, PC and M Tushman (1990). Technological dis-continuities and dominant designs: A cyclical model of technological change. Administrative Science Quarterly, $35,604-633$. 
Christensen, CM (1992). Exploring the limits of the technology S-curve. Part I: components technologies. Production and Operations Management, 1, 334-357.

Christensen, CM and JL Bower (1996). Customer power, strategic investment, and the failure of leading firms. Strategic Management Journal, 17, 197-218.

Christensen, CM and RS Rosenbloom (1995). Explaining the attacker's advantage: Technological paradigms, organizational dynamics, and the value network. Research Policy, 24, 233-257.

Christensen, CM (1997). The Innovator's Dilemma: When New Technologies Cause Great Firms to Fail. Boston, MA: HBS Press.

Christensen, CM, ME Raynor and R Mcdonald (2015). What is disruptive innovation. Harvard Business Review, December, pp. 44-53.

Clark, KB (1985). The interaction of design hierarchies and market concepts in technological evolution. Research Policy, 14(12), 235-251.

DiMaggio, PJ and WW Powell (1983). The iron cage revisited: Institutional isomorphism and collective rationality in organizational fields. American Sociological Review, 48(2), 147-160.

Ernkvist, M (2015). The double knot of technology and business-model innovation in the era of ferment of digital exchanges: The case of OM, a pioneer in electronic options exchanges. Technological Forecasting and Social Change, 99, 285-299.

Findahl, O and P Davidsson (2015). Svenskarna och internet 2015, utdrag om sociala medier. Stockholm: InternetstiftelseniSverige.

Foster, RJ (1986). Innovation: The Attacker's Advantage. New York: Summit Books.

Garud, R, S Jain and A Kumaraswamy (2002). Institutional entrepreneurship in the sponsorship of common technological standards: The case of Sun Microsystems and Java. Academy of Management Journal, 45, 196-214.

Henderson, RM (1993). Underinvestment and incompetence as responses to radical innovation: Evidence from the photolithographic alignment equipment industry. The Rand Journal of Economics, 24, 248-270.

Jacobsson, S and A Bergek (2004). Transforming the energy sector: The evolution of technological systems in renewable energy technology. Industrial and Corporate Change, 13(5), 815-849.

Laurell, C and C Sandström (2014). Disruption and social media: Entrant firms as institutional entrepreneurs. International Journal of Innovation Management, 18(3), 1-17.

Peng, MW, SL Sun, B Pinkham and H Chen (2009). The institutions based view as a third leg for a strategy tripod. Academy of Management Perspectives, 23(4), 63-81.

Pihl, C (2013). When customers create the ad, and sell it: A value network approach. Journal of Global Scholars of Marketing Science, 23(2), 127-143.

Pihl, C and C Sandström (2013). Value creation and appropriation in social media: The case of fashion bloggers in Sweden. International Journal of Technology Management, 61(3/4), 309-323.

Pihl, C (2014). Brand, community and style: Exploring linking value in fashion blogging. Journal of Fashion Marketing and Management, 18(1), 3-19. 
Sahal, D (1985). Technological guideposts and innovation avenues. Research Policy, $14(2), 61$.

Sandström, C (2011). High-end disruptive technologies with an inferior performance. International Journal of Technology Management, 56(2-4), 109-122.

Sandström, C, H Berglund and M Magnusson (2014). Symmetric assumptions in the theory of disruptive innovation: Theoretical and managerial implications. Creativity and Innovation Management, 23(4), 472-483.

Saunders, A (1986). Technology and the Regulation of Financial Markets: Securities, Futures, and Banking. Lexington, MA: Lexington Books.

Stieglitz, S, L Dang-Xuan, A Bruns and C Neuberger (2014). Social media analytics. Business \& Information Systems Engineering, 6(2), 89-96.

Tripsas, M (2008). Customer preference discontinuities, Managerial and Decision Economics, 29(2-3), 79-97.

Tripsas, M (1997). Unraveling the process of creative destruction: Complementary assets and incumbent survival in the typesetter industry. Strategic Management Journal, 18(1): 119-142.

Utterback, JM (1994). Mastering the Dynamics of Innovation. Cambridge, MA: Harvard University Press. 